Document downloaded from:

http://hdl.handle.net/10251/99662

This paper must be cited as:

Barbara Torregrosa-Jaime; López-Navarro, A.; Corberán, JM.; Esteban-Matías, JC.; Klinkner, L.; Payá-Herrero, J. (2013). Experimental analysis of a paraffin-based cold storage tank. International Journal of Refrigeration. 36(6):1632-1640.

doi:10.1016/j.ijrefrig.2013.05.001

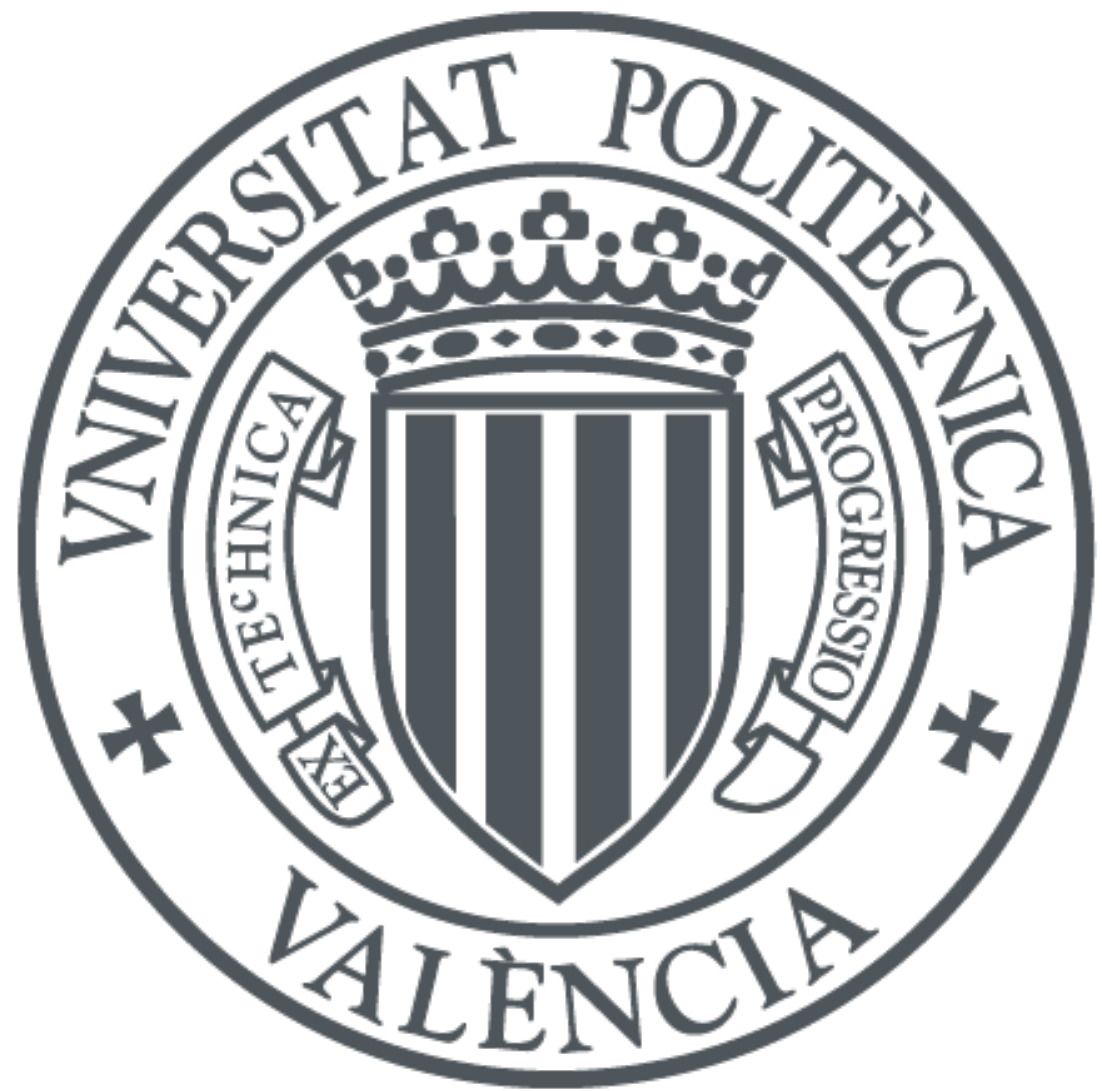

The final publication is available at

http://dx.doi.org/10.1016/j.jjrefrig.2013.05.001

Copyright Elsevier

Additional Information 


\title{
Experimental analysis of a paraffin-based cold storage tank
}

\author{
B. Torregrosa-Jaime ${ }^{\mathrm{a}}$, A. López-Navarro ${ }^{\mathrm{a}}$, \\ J.M. Corberána , J.C. Esteban-Matías ${ }^{b}$, L. Klinkner ${ }^{c}$, J. Payáa $^{a}{ }^{*}$
}

a Instituto de Ingeniería Energética IIE (Universidad Politécnica de Valencia) Camino de Vera s/n, Edificio 8E cubo F 5a planta, 46022 Valencia, Spain

${ }^{b}$ ACCIONA Infraestructuras S.A. Centro Innovación Tecnológica

C/ Valportillo II, 8, 28108 Alcobendas Madrid, Spain

${ }^{\mathrm{c}}$ Rubitherm Technologies $\mathrm{GmbH}$, Sperenberger Str. 5a, D-12277 Berlin, Germany

\section{Abstract}

The aim of this study is to characterize a paraffin-based cold storage tank. Novel experimental results are presented for this system which combines a significant amount of paraffin $(1450 \mathrm{~kg})$ immersed around 18 spiral-shaped coils disposed in counter-current flow. The paraffin has a phase-change temperature in the range $4-8^{\circ} \mathrm{C}$ as measured by a 3-layer calorimeter. Different tests have been carried out with a constant mass flow rate and supply temperature. Around $31 \%$ of the paraffin has hardly any contact with the coils and hereby acts as a dead mass. The results show the importance of natural convection within the phase-change-material, particularly during the melting process. The highest efficiency has been achieved for the lowest supply temperatures and mass flow rates of the heat transfer fluid. 
Keywords: Experiment, latent heat storage, phase change material, paraffin, cold storage

${ }^{*}$ Corresponding author. Tel: +34 963879910; Fax: +34 963877272;

E-mail address: jorpaher@iie.upv.es (J. Payá)

\begin{tabular}{|c|c|c|c|}
\hline \multicolumn{4}{|c|}{ NOMENCLATURE } \\
\hline $\mathrm{T}$ & Temperature, ${ }^{\circ} \mathrm{C}$ & $\mathrm{C}_{\mathrm{p}}$ & Specific heat $\left(\mathrm{J} \mathrm{kg}^{-1} \mathrm{~K}^{-1}\right)$ \\
\hline$\Delta \mathrm{h}$ & Latent heat $\left(\mathrm{kJ} \mathrm{kg}^{-1}\right)$ & $\dot{Q}$ & Thermal power $(\mathrm{W})$ \\
\hline$\Delta \mathrm{t}$ & $\begin{array}{l}\text { Duration of the latent heat } \\
\text { process (h) }\end{array}$ & RMSE & Root-mean-square-error \\
\hline$\dot{W}_{\text {elec }}$ & $\begin{array}{l}\text { Power consumption of the pump } \\
\text { and compressor (W) }\end{array}$ & $\overline{C O P}$ & $\begin{array}{l}\text { Mean coefficient of } \\
\text { performance in the charge } \\
\text { tests }\end{array}$ \\
\hline$\dot{m}$ & Mass flow rate, $\mathrm{kg} \mathrm{s}^{-1}$ & $\mathrm{~N}$ & $\begin{array}{l}\text { Number of measurements in } \\
\text { a charge or discharge test }\end{array}$ \\
\hline$\alpha, \beta, \gamma$ & Fitting parameters in Eq. (2) & $\mathrm{Re}$ & Reynolds number \\
\hline Dint & Coil internal diameter, $\mathrm{cm}$ & Dext & Coil external diameter, $\mathrm{cm}$ \\
\hline \multicolumn{4}{|c|}{ Subscripts } \\
\hline supply & LHS tank supply temperature & return & LHS tank return temperature \\
\hline LHS & Latent Heat Storage & HTF & Heat Transfer Fluid \\
\hline HEX & Heat exchanger & $\exp$ & Experimental \\
\hline
\end{tabular}




\begin{tabular}{|llll|}
\hline c & Cooling loop & H & Heating loop \\
liq & Liquid & sol & Solid \\
m & Melting & & \\
\hline
\end{tabular}

\section{INTRODUCTION}

Due to the increasing demand of refrigeration, a key point in the next years is to develop more efficient cold generation and storage technologies. In this context, Latent Heat Storage (LHS) is potentially interesting because of the high volumetric capacity and low heat transfer losses (ASHRAE, 2007; Mehling and Cabeza, 2008; Dincer and Rosen, 2011) among other reasons.

Many Phase Change Materials (PCMs) are nowadays being tested (Osterman et al., 2012, Oró et al., 2012, Zalba et al., 2003), each of them with specific thermophysical properties. In the temperature range which is useful for air-conditioning (-5 to $10^{\circ} \mathrm{C}$ ) the main options which are available are ice storage, hydrated salts, ice slurries or paraffins. The latter can be more energy-efficient than ice storage as the solidification can be realised with higher evaporation temperatures with the consequent benefits on the chiller performance. Moreover, the lower the temperature difference with respect to the ambient, the lower the heat transfer losses.

Paraffins present the advantage of being harmless, non-toxic, relatively cheap and compatible with metal containers. Furthermore, the stability of paraffins has been proved to be very good even for 5000 cycles (Sarı et al., 2009).

Nevertheless, paraffins present the drawback of having a low thermal conductivity. For this reason, some authors (Sarı, 2004; Marín et al., 2005) have 
focused on developing paraffin-composite materials (higher thermal conductivity) or encapsulated PCM solutions (Sarı et al., 2009; Cho and Choi, 2000; Zukowski, 2007; Nallusamy et al., 2007) with a large heat transfer area and a small thermal diffusion distance within the PCM. Another drawback of paraffins is the flammability, although in this case the flash point is $122^{\circ} \mathrm{C}$ is not a risk, at least on a laboratory scale.

Previous studies have shown that the performance of paraffin-based storage tanks depends mainly on the supply temperatures and mass flow rates of the heat transfer fluid (Cho and Choi, 2000; Zukowski, 2007; Akgun et al., 2008). Generally, LHS systems have been studied with small amounts of paraffin, less than $10 \mathrm{~kg}$ (Marín et al., 2005; Akgun et al., 2008) or around 100 kg (Zukowski, 2007; Banaszek et al., 1999). Extensive experimental and numerical work has also been done at the University of South Australia (Tay et al., 2012a, Tay et al., 2012b. Tay et al., 2013) concerning tube-in-tank PCM systems with $27.6 \mathrm{~kg}$ up to $179.2 \mathrm{~kg}$ of water or salt hydrates. In many practical applications, even larger amounts of PCM are required to reach a sufficient capacity.

Given the actual state of the art, the present work introduces a novel aspect which is combining a tank with a significant amount of paraffin $(1450 \mathrm{~kg})$ with a heat exchanger based on spiral-shaped coils in counter-current flow. A previous study (Banaszek et al., 1999) on a spiral-shaped cylinder with similarities to the present work showed that the free convection mechanisms in such tanks are complex and should be studied carefully.

This paper presents a complete analysis of (i) the temperatures in the PCM, (ii) the temperatures of the heat transfer fluid and (iii) the overall performance of the installation in terms of the thermal capacity and electric power consumption. 


\section{EXPERIMENTAL SET-UP}

\subsection{Installation and measurement procedure}

The experimental installation (López-Navarro et al., 2012; López-Navarro et al., 2013) is located at the Polytechnic University of Valencia (Spain). The set-up, which is shown in Fig.1, has been designed to characterize LHS systems within a temperature range from -10 to $100^{\circ} \mathrm{C}$.

Basically, the installation consists of a heating and cooling circuit which allow to heat or cool the heat transfer fluid of the thermal storage tank. All of the components, as well as the uncertainty of the measurement equipment, have been presented in recent literature (López-Navarro et al., 2012; López-Navarro et al., 2013). For this reason, the present publication focuses in updating the recent modifications in the test bench.

The cold-storage tank is a CALMAC ICEBANK 1098C (CALMAC, 2013). Originally, the tank has been designed for ice-storage but in this study, it has been filled with the paraffin RT8 (RUBITHERM, 2013). The tank is mainly made out of plastic, the coils do not have any fins, and the purchase cost including transport was of $8000 €$, probably less than for other tanks with a similar capacity, but with more expensive materials (stainless stell for instance) and more complex heat exchangers (e.g. plate heat exchangers). The aim is to evaluate the performance of this rather simple and cheap storage tank when filled with a paraffin instead of with ice. Among the available PCM materials for cold storage (Oró et al., 2012) at this temperature level, a paraffin has been chosen mainly because of its long term stability. 
The storage tank, which is illustrated schematically in Fig.2, consists of 34 counter current spiral-shaped tubes immersed in the phase-change material. The tubes have an outer diameter of $1.8 \mathrm{~cm}$ and a horizontal spacing of $2.3 \mathrm{~cm}$. Using spiral-shaped coils helps to achieve a high volumetric PCM capacity and an enhanced heat transfer in the HTF due to the centrifugal forces (VDI, 2010).

The coils (Fig.2) are made of polyethylene and are placed on horizontal planes. Their total length is of around $70 \mathrm{~m}$ in spirals of 17 turns. As in recent investigations (López-Navarro et al., 2012; López-Navarro et al., 2013), the tank has been tested at a partial load by blocking the top 16 coils with plumbing accessories for polyethylene pipes. Thus, the HTF only circulates through the bottom 18 coils, which are the only ones surrounded by the paraffin. A special attention has to be paid to the compatibility between the paraffin and the heat exchanger. Within this short experimental campaign (around one month) no problems have been detected, but on a long-term the paraffin would tend to diffuse through the polyethylene (CALMAC, 2013) and could eventually deteriorate the spiral-shaped coils. In a real installation stainless stell or other compatible materials should be used but in this case, on a laboratory scale, it was more simple to use the original coils from the ice storage tank.

Fig. 3 shows the distribution of thermocouples inside the storage tank. The thermocouples ТРСм1-6 are all T-Type and have been placed to measure the PCM temperature in different vertical positions in the center and outer part of the tank, as these are the only regions which have an easy access. The first column of thermocouples ТРсм1-3 (white zone) measures the temperatures of the paraffin which is in the central region of the tank. The outer column of thermocouples TРсм4-6 is located in the grey zone and measures the PCM temperature exactly in the middle 
between two adjacent tubes in the outer part of the spirals. The end of all thermocouples (reference junction end) are placed together in an isotherm oil bath following published measurement procedure (Burns et al., 1993) to measure the PCM temperature with an accuracy of $\pm 0.15 \mathrm{~K}$ using functions from the National Institute of Standards and Technology (NIST) for the voltage/temperature conversion.

The supply and return temperatures of the HTF ( $T_{\text {supply }}$ and $T_{\text {return in Fig. } 1) \text { are }}$ of particular interest as they enable the calculation of the charge and discharge power. Thus, they have been measured with RTD thermal resistances PT100 1/10 DINB with an accuracy of $\pm 0.03 \mathrm{~K}$.

The mass flow rate of the HTF is measured by means of a SIEMENS CORIOLIS flow meter with an uncertainty of $\pm 7.3 \mathrm{~kg} \mathrm{~h}^{-1}$. The mass flow rate and temperature measurements are fully monitored by means of a datalogger Agilent $34970 \mathrm{~A}$ and a three 22 channels multiplexer HP 34901A with a recording interval of $30 \mathrm{~s}$. The instrumentation shown in Fig. 1 and Fig. 3 is located in one of the multiplexers, whereas the other 2 multiplexers are used to monitor temperature measurements in the heating and cooling loops.

\subsection{Thermal properties of the tested paraffin}

Paraffin waxes consist of saturated hydrocarbons $\mathrm{C}_{n} \mathrm{H}_{2(n+1)}$ and their thermal properties can be tailored towards a specific application depending on the number of carbon atoms. In order to reach melting temperatures between 5 and $10{ }^{\circ} \mathrm{C}$, tetradecanes ( $n=14)$ or pentadecanes $(n=15)$ are generally used (Oró et al., 2012, Cho and Choi, 2000; Bo et al., 1999). 
Before analysing the dynamics of the freezing and melting inside the tank, it is first convenient to characterize the PCM material separately. The tested RT8 material has been analyzed with a 3-layer calorimeter placed in a standard climatic chamber. An average cooling/heating rate of $0.03 \mathrm{~K} \mathrm{~min}^{-1}$ has been applied to a sample of 100 g.

Fig. 4 shows the enthalpy-temperature curves of the paraffin RT8 during the melting (heating) and freezing (cooling). As may be inferred from Fig. 4, the phasechange in the paraffin is rather smooth and takes place mainly in the temperature region between 4 to $8^{\circ} \mathrm{C}$. The exact melting and freezing temperatures are $1.90{ }^{\circ} \mathrm{C}$ and $8.48{ }^{\circ} \mathrm{C}$ respectively, as obtained by intersecting the maximum slope of the curves and the base line.

Other useful thermo-physical properties of the paraffin are shown in Table 1, as provided by the manufacturer (RUBITHERM, 2013). The low thermal conductivity $\left(0.2 \mathrm{Wm}^{-1} \mathrm{~K}^{-1}\right)$ is responsible for the low heat conduction which is observed in the tests and could be compensated with a smaller pitch between tubes, or by adding fins.

\section{RESULTS AND DISCUSSION}

Table 2 presents a summary of the mass flow rate and supply temperature of the tests which have been applied to charge and discharge the tank. Supply temperatures in the range $1-5^{\circ} \mathrm{C}$ and $11-15^{\circ} \mathrm{C}$ have been tested in the charge and discharge tests respectively. 
Table 2 also presents the values of two key experimental parameters which are the mass flow rate and the supply temperature. The tested mass flow rates are in the range from 2000 to $4000 \mathrm{~kg} \mathrm{~h}^{-1}$. In this particular application with spiral-shaped coils, the centrifugal forces in the HTF induce secondary flows. The latter have a stabilizing effect on the flow and thus the transition from laminar to turbulent flow is shifted to higher Reynolds numbers (VDI, 2010). Given the curvature of the coils, the critical Reynolds number is of around 5134 and hereby, all of the tests in Table 2 are essentially in laminar flow.

In subsections 3.1 and 3.2, the typical temperature profiles and thermal power are presented. Finally, the thermal capacity and the electric energy consumption are discussed in subsection 3.3.

\subsection{Charge tests}

The temperatures in the PCM have been plotted in Fig. 5 for the charge test C9. The temperature profiles are similar to those of other paraffin-based systems (Cho and Choi, 2000; Akgun et al., 2008; Bo et al., 1999). During the first 50 minutes, the sensible heat transfer region is clearly observed until a temperature between $7{ }^{\circ} \mathrm{C}$ and $8{ }^{\circ} \mathrm{C}$ is reached in the $\mathrm{PCM}$, in agreement with the enthalpy curves of the material which are shown in Fig. 4.

As in many practical installations with no thermal buffer after the LHS tank, the return temperature cannot be instantaneously decreased down to the target setpoint. This is due to the limited capacity of the chiller and to the thermal power which can be exchanged instantaneously by the heat exchanger of the cooling loop. After 
100 minutes approximately, the target temperature of $1^{\circ} \mathrm{C}$ is reached and becomes stable.

Due to the low thermal conductivity of the paraffin, the central region of the tank, which only has two vertical collectors, has a very small heat transfer surface and hereby the PCM has almost a constant temperature (close to the melting temperature) throughout the complete test.

After around 500 minutes, the temperatures TPCM4-6 smoothly decrease towards the supply temperature, in agreement with the enthalpy of the material which also decreases progressively in the region $2-5^{\circ} \mathrm{C}$.

Fig. 6 illustrates the temperature measurements of the PCM during an additional charge test which has been realized to observe a full load of the tank. In this test, a very low supply temperature has been applied $\left(-5^{\circ} \mathrm{C}\right)$. Even with such a temperature difference between the supply temperature and the freezing temperature of the PCM, the central region still stays at a constant temperature of around $7^{\circ} \mathrm{C}$. The final part of the latent heat transfer region seems to be marked by a change in the slope of the PCM temperature, at approximately $1{ }^{\circ} \mathrm{C}$ which corresponds to the base of the enthalpy curves in Fig. 4.

When working on a system level, the thermal power which is exchanged with the HTF is a key point. The thermal power has been expressed in Eq. (1) as a function of the temperature difference between the supply and return of the HTF:

$$
\dot{Q}_{L H S}=\dot{m}_{H T F} \cdot C_{p, H T F} \cdot\left|T_{\text {supply }}-T_{\text {return }}\right|
$$

Fig. 7 shows the thermal power of the charge test C9 on the left y-axis, and the supply and return temperatures of the HTF on the right y-axis. In the sensible heat 
transfer region (first 50 minutes as from Fig. 5) the thermal power decreases rapidly. Once a temperature of around $7-8^{\circ} \mathrm{C}$ is reached in the PCM, as shown in Fig. 5 the enthalpy of the material decreases progressively and so does the exchanged thermal power.

In Fig. 8, the thermal power of the full charge with a supply temperature of $-5^{\circ} \mathrm{C}$ has also been represented. In this case the thermal power decreases very clearly after around 460 minutes which is when the set-point temperature of $-5^{\circ} \mathrm{C}$ is finally reached and when the thermocouples TРсM4-6 present temperatures between 0 and 3 ${ }^{\circ} \mathrm{C}$ corresponding to the base of the enthalpy curves in Fig. 4.

\subsection{Discharge tests}

During the discharge tests, the PCM is melted by applying supply temperatures in the range from 11 to $15^{\circ} \mathrm{C}$. Fig. 9 shows a sample of one test, number D8 which has a mean supply temperature of $12.8^{\circ} \mathrm{C}$. The temperature inside the PCM should be analysed together with Fig. 10, where the cooling power has been represented.

During the first 30 to 90 minutes, the PCM temperatures TPCM4-6 increase with a similar slope until a temperature of $4^{\circ} \mathrm{C}$ is reached, which is approximately the beginning of the latent heat transfer region. The PCM changes from solid to liquid state concentrically around the coils, as the highest temperatures are achieved in the wall of the coils. As also shown by other authors (Bo et al., 1999; Bo and Setterwall, 2002), the initial freezing point in the charge tests can be easily observed (Figs. 5 and 6), but the melting process takes place in a wider temperature range.

Between 90 and 400 minutes in Fig. 9, as the liquid layer grows, the solid blocks between two adjacent coils become free and due to the buoyancy effect they 
tend to sink towards the bottom of the tank. This is the reason for the temperature oscillations which are observed in this region, particularly between 8 and $10^{\circ} \mathrm{C}$. The temperature oscillations are mainly observed in ТРСм5-6 which are located in the bottom of the tank.

In all of the discharge tests, for instance after 400 minutes in Fig. 9, the temperatures ТРСм4-6 cross because at this given point the liquid which was held between the walls of the coils and the liquid-solid layer becomes free and floats towards the top of the tank due to the buoyancy effect. Thus, after 400 minutes, the hottest temperatures are observed in the upper region of the tank. In terms of cooling power, this moment is approximately when the cooling power decreases down to zero. On the one hand, most of the PCM is entering the sensible heat transfer region, and on the other hand the convective thermal resistance is much smaller than the conductive thermal resistance. These two aspects induce a rapid decrease of the cooling power after 400 minutes.

\subsection{Overall performance}

In any practical installation, two key aspects are the storage capacity and the duration of the melting and solidification process. In the following paragraphs, these two points are discussed.

The energy which is exchanged with the HTF can be obtained directly by integrating Eq. (1). In Fig. 11, the charged energy has been represented for tests with a similar mass flow rate and supply temperature.

The colder the supply temperature and the higher the mass flow rate, the higher the capacity for a same charge duration. For any given capacity, the faster charge tests are achieved with high mass flow rates and low supply temperatures. In the 
tested operating conditions (2000 to $4000 \mathrm{~kg} \mathrm{~h}^{-1}$ and 1 to $5{ }^{\circ} \mathrm{C}$ ) the mass flow rate has a smaller effect on the capacity and duration than the supply temperature.

In all tests, a minimum capacity of $40 \mathrm{kWh}$ is reached, which corresponds to a mass of around $1007 \mathrm{~kg}$. Given that the tank has been filled with $1450 \mathrm{~kg}$ of paraffin, this implies that at least $69 \%$ of the paraffin is reacting. In fact, the remaining $31 \%$ is approximately the mass which is contained in the dead volume in the center of the spirals and in the base of the tank, and it hardly reacts if the tests are realized under reasonable durations for practical applications (5-11 hours).

The effect of the operating conditions on the discharged energy is analyzed in Fig. 12. Once again, the temperature difference between the supply temperature and the melting temperature acts as a driving force, together with the mass flow rate. In general terms, high mass flow rates and supply temperatures help to achieve faster tests with a higher discharged energy. Nevertheless, in this case the effect of the mass flow rate is higher than in the charge tests. This aspect is explained in the discussion on the duration of the melting process.

The duration of the latent heat transfer process has been measured experimentally as the time which is necessary for the reference thermocouple TРсм4 to reach a temperature of $4^{\circ} \mathrm{C}$ (in all charge tests except $\mathrm{C} 1, \mathrm{C} 4$ and $\mathrm{C} 7$ which have a supply temperature of $5{ }^{\circ} \mathrm{C}$ ) or $8^{\circ} \mathrm{C}$ (in all discharge tests). This thermocouple has been chosen among all thermocouples as the most representative of the mean PCM temperature given the fact that it is located at mid-height of the tank, and relatively close to the coils on the contrary to the thermocouples ТРсм1-3 which are in the inner core of the tank. 
The empirical Eq. (2) has been proposed to predict the effect of the mass flow rate and supply temperature on the duration of the tests. The weight of these two variables depends on the parameters $(\alpha, \beta, \gamma)$ as given in Eq. (2):

$$
\Delta t=\frac{\beta}{\left|T_{\text {supply }}-T_{P C M}\right|^{\gamma} \cdot \dot{m}_{H T F}{ }^{\alpha}}
$$

Where ТРсм is the characteristic temperature of the phase-change material, in other words the melting temperature in the discharge tests and the freezing temperature in the charge tests. The 3 parameters $(\alpha, \beta, \gamma)$ in Eq. (2) have been fitted using the Excel solver pane to minimize the root-mean-square-error (RMSE) between the experimental and the predicted values, as indicated in Eq. (3).

$$
R M S E=\sqrt{\frac{\sum\left(\Delta t_{\text {exp }, i}-\Delta t_{\text {correlation }, i}\right)}{N}}
$$

Fig. 13 shows the duration of the tests, as predicted by the empirical Eq. (2). The proposed correlation fits perfectly with the experimental tests as can be inferred from the low RMSE values which are achieved. The highest deviation between the predicted and measured duration is $3.4 \%$ and $5.5 \%$ in the charge and discharge tests respectively.

The fitting parameters $(\alpha, \beta, \gamma)$ are also given in Fig. 12, and show that the effect of the supply temperature is higher than the mass flow rate within the tested range of conditions. In both the charge and discharge tests, the effect of the mass flow rate is small as may be inferred from the low $\alpha$ values. During the charge tests, a 
solid layer is formed concentrically around the coils. As the thermal conductivity of the PCM is low, the growing solid layer tends to isolate the solid/liquid boundary from the coil. Consequently, the impact of the supply temperature ( $\gamma$ value) is higher for the freezing process.

During the charge tests, the main power consumption derives from the compressor of the chiller and the circulation pump of the HTF. As the thermal capacity of the charge tests is very different (Fig. 10) and is specific to this particular storage tank, it is more convenient to compare the specific power consumption of the system, as expressed in Eq. (4).

$$
\frac{1}{\overline{C O P}}=\frac{\int_{t 0}^{t \infty} \dot{W}_{\text {elec }}}{\int_{t 0}^{t \infty} \dot{Q}_{L H S}}
$$

Fig. 13 shows the specific energy consumption of the charge tests. The pump power consumption throughout the charge tests is much smaller than the compressor power consumption.

For sufficiently high time values in Eq. (4), the electric power consumption increases with no significant increase in the storage capacity. Hence, the instantaneous COP decreases. For this reason, the values shown in Fig. 13 are given for the time period between $\mathrm{t}=0 \mathrm{~s}$ and the point when the instantaneous COP of the system drops below 0.5 which happens after the latent heat transfer period.

In terms of overall efficiency in Fig. 13, the highest $\overline{C O P}$ corresponds to the lowest specific energy consumption, and is achieved for the charge tests with low supply temperatures. As the effect of the mass flow rate is not so relevant on the charge duration, a low mass flow rate is also preferable. A mean specific energy 
consumption of 0.50 is obtained for the whole series of charge tests C1-C9. In recent work from the authors (López-Navarro et al., 2012) the same tank was charged with ice instead of with the RT8 paraffin, reaching a mean specific energy consumption of 0.56 in the charge tests. In other words, the $\overline{C O P}$ has been observed to be slightly higher (2.03) with the RT8 paraffin than with ice (1.80). Nevertheless, a more extensive comparison of the energy efficiency of cold storage with ice and paraffin needs to be carried out and is planned as future work.

\section{CONCLUSIONS}

In this study, a paraffin-based cold storage tank has been analyzed. Different tests have been performed to investigate the effect of the mass flow rate and supply temperature of the HTF. The tested paraffin has been first characterized by means of a 3-layer calorimeter and the dynamic temperatures inside the PCM tank are in agreement with the enthalpy-temperature curves.

The following conclusions have been obtained:

- In all tests, the centre of the tank, as well as its base, is filled with paraffin which can hardly react. This leads to a dead mass of up to $31 \%$.

- In the charge tests (solidification), the initial freezing point is clearly observed in the PCM temperature measurements. The solid layer which is progressively formed tends to isolate the wall of the coils from the solid-liquid boundary layer due to the low thermal conductivity of the paraffin. For this reason the effect of the supply temperature is much more relevant than the effect of the mass flow rate. 
- In the discharge tests, a melting temperature range is observed in the PCM measurements. Once the solid blocks of paraffin become free, they tend to sink towards the bottom of the tank due to the buoyancy effect.

- The highest electric power consumption of the installation derives from the compressor of the chiller. The most energy-efficient operation has been achieved for low supply temperatures and mass flow rates. Low supply temperatures help to fasten the charge process and reduce the total power consumption of the chiller, whereas the mass flow rate only has a minor impact on the solidification process and should hereby be limited in this installation. The freezing process has proved to be slightly more energyefficient with the tested paraffin than in recent tests with ice storage.

\section{ACKNOWLEDGEMENTS}

The authors gratefully acknowledge the fundings from ACCIONA Infraestructuras.

\section{REFERENCES}

Akgün, M., Aydn, O., Kaygusuz, K., 2008. Thermal energy storage performance of paraffin in a novel tube-in-shell system. Appl. Therm. Eng. 28, 405-413. ASHRAE, 2007. ASHRAE HANDBOOK, HVAC Applications. 
Banaszek, J., Domanski, R., Rebow, M., El-Sagier, F., 1999. Experimental study of solid-liquid phase change in a spiral thermal energy storage unit. Appl. Therm. Eng. $19,1253-1277$.

Bo, H., Gustafsson, E.M., Setterwall, F., 1999. Tetradecane and hexadecane binary mixtures as phase change materials (PCMs) for cool storage in district cooling systems. Energy 24, 1015-1028.

Bo, H., Setterwall, F., 2002. Technical grade paraffin waxes as phase change materials for cool thermal storage and cool storage systems capital cost estimation. Energy Convers. Manage. 43, 1709-1723.

Burns, G.W., Scroger, M.G., Strouse, G.F., Croarkin, M.C., Guthrie, W.F., 1993. Temperature-electromotive force reference functions and tables for the letterdesignated thermocouple types based on the ITS-90, NIST Monograph 175.

CALMAC, 2013. Available at <www.calmac.com>.

Cho, K., Choi, S.H., 2000. Thermal characteristics of paraffin in a spherical capsule during freezing and melting processes. Int. J. Heat Mass Transfer 43, 3183-3196.

Dincer, I., Rosen, M.A., 2011. Thermal Energy Storage, Systems and Applications. John Wiley and Sons, Chichester.

López-Navarro, A., Biosca-Taronger, J., Torregrosa-Jaime, B., Corberán, J.M., BoteGarcía, J.L., Payá, J., 2013. Experimental investigations on the influence of ice floating in an internal melt ice-on-coil tank. Energ. Build. 57, 20-25.

López-Navarro, A., Biosca-Taronger, J., Torregrosa-Jaime, B., Martínez-Galván, I., Corberán, J.M. , Esteban-Matías, J.C. , Payá, J., 2012. Charging performance of an ice-storage installation. Int. J. Refrigeration, In Press, http://dx.doi.org/10.1016/j.jirefrig.2012.09.008. 
Marín, J.M., Zalba, B., Cabeza, L.F., Mehling, H., 2005. Improvement of a thermal energy storage using plates with paraffin-graphite composite. Int. J. Heat Mass Transfer 48, 2561-2570.

Mehling, H., Cabeza, L.F., 2008. Heat and cold storage with PCM: An up to date introduction into basics and applications. Springer, Berlin.

Nallusamy, N., Sampath, S., Velraj, R., 2007. Experimental investigation on a combined sensible and latent heat storage system integrated with constant/varying (solar) heat sources. Renew. Energ. 32, 1206-1227.

Oró, E., de Gracia, A., Castell, A., Farid, M.M., Cabeza, L.F., 2012. Review on phase change materials (PCMs) for cold thermal energy storage applications. Appl. Energ. $99,513-533$

Osterman, E., Tyagi, V.V., Butala, V., Rahim, N.A., Stritih, U., 2012. Review of PCM based cooling technologies for buildings. Energ. Build. 49, 37-49.

RUBITHERM, 2013. Available at <www.rubitherm.de>.

Sarı, A., 2004. Form-stable paraffin/high density polyethylene composites as solidliquid phase change material for thermal energy storage: preparation and thermal properties. Energy Convers. Manage. 45, 2033-2042.

Sarı, A., Alkan, C., Karaipekli, A., Uzun, O., 2009. Microencapsulated n-octacosane as phase change material for thermal energy storage. Solar Energy 83, 1757-1763. Tay, N.H.S., Bruno, F., Belusko, M., 2012a. Experimental investigation of tubes in a phase change thermal energy storage system. Appl. Energ. 90, 288-297.

Tay, N.H.S., Bruno, F., Belusko, M., 2012b. Experimental validation of a CFD model for tubes in a phase change thermal energy storage system. Int. J. Heat Mass Transfer 55, 574-585. 
Tay, N.H.S., Bruno, F., Belusko, M., 2013. Experimental investigation of dynamic melting in a tube-in-tank PCM system. Appl. Energ. 104, 137-148.

VDI Gesellschaft Verfahrenstechnik und Chemieingenieurwesen, 2010. VDI Heat Atlas. Springer, Berlin.

Zalba, B., Marín, J.M., Cabeza, L.F., Mehling, H., 2003. Review on thermal energy storage with phase change: materials, heat transfer analysis and applications. Appl. Therm. Eng. 23 (3), 251-283.

Zukowski, M., 2007. Mathematical modeling and numerical simulation of a short term thermal energy storage system using phase change material for heating applications. Energy Convers. Manage. 48, 155-165. 